\title{
PENSANDO O FÓRUM SOCIAL MUNDIAL ATRAVÉS DO FEMINISMO
}

\author{
MARIA BETÂNIA ÁVILA \\ SOS CORPO - Gênero e Cidadania
}

Resumo: Este artigo introduz algumas questões inspiradas pelo Fórum Social Mundial que dizem respeito às relações entre os movimentos sociais e o projeto de transformação social, interpretado como processo político de superação das formas de exploração, dominação e discriminação presentes na sociedade. Compreende-se essa transformação na perspectiva de uma democracia radical, ou seja, na democratização da própria esfera política no campo da esquerda.

Palavras-chave: movimento feminista, democracia, conflito, transformação, reconhecimento.

Existem várias correntes ou pensamentos feministas e essa é uma questão já dita e discutida em vários lugares. Reconheço a diversidade de visões nesse campo. Aqui não quero entrar nessa discussão, mas apenas reconhecer isso e dizer que falo de um determinado lugar do feminismo para assim me sentir confortável para fazer análises e emitir opiniões feministas. Outro ponto que quero esclarecer é que as idéias aqui expressas têm como pano de fundo a minha experiência no Fórum Social Mundial de 2001, 2002 e 2003 na cidade de Porto Alegre. A isso quero acrescentar que não vejo o Fórum Social Mundial como um evento, mas como um processo que aglutina e revela a capacidade e a diversidade de organizações políticas dos movimentos sociais espalhadas e em articulação pelo mundo. A chegada ao lugar do Fórum Social Mundial é um longo caminho, tanto no tempo como no espaço geográfico. Um tempo histórico e contemporâneo, que tanto se constrói com raízes como com rupturas com o passado. Uma geografia com sentido político, em que as origens das/os participantes são dados importantes na perspectiva de construir um mundo comum, de romper fronteiras e ampliar o internacionalismo da luta pela transformação social.

A presença das mulheres no Fórum Social Mundial é marcante. Não sei o exato significado quantitativo, mas, quando se olha, se vêem as mulheres tão presentes quanto os homens pelos vários lugares onde o movimento acontece. Mas nas grandes mesas ou nos grandes painéis, aí mesmo sem contar, já se percebe que o quadro se altera e a presença das mulheres é menos marcante. A presença do movimento feminista - que significa algo diferente da presença das mulheres, mas para o qual a presença das mulheres

Copyright ( 2003 by Revista Estudos Feministas

' Virginia VARGAS, 2003, p. 59. 
importa - é evidente através das manifestações, da participação nas mesas e painéis, nas oficinas e em todos os cantos onde se mostram, se vendem, se distribuem livros, panfletos, cartilhas e cartazes. A evidência da presença do movimento feminista não significa, no entanto, que ele esteja de fato em relação de igualdade com outros sujeitos ali presentes. "Os tempos de cada um são diferentes. Digo isso no sentido de coisas muito concretas. Por exemplo, no segundo FSM, fui a um grande painel com 11 pessoas, eram 11 homens. Saí. Não sei se diziam coisas interessantes, mas é uma coisa ética. Simplesmente saí. Creio que isso é algo a ser superado no próximo Fórum."' O feminismo como pensamento e prática política é parte daquele lugar e daquela construção, e parte dessa construção é a superação das relações desiguais de poder que ainda constituem esse espaço político em movimento.

Se coloco essas ilustrações iniciais é com a intenção de introduzir algumas questões que a existência do Fórum Social Mundial, do meu ponto de vista, nos impõe a pensar. Essas questões dizem respeito à relação entre os movimentos sociais e o projeto de transformação social, entendido aqui, de forma sintética, como o processo político para superação de todas as formas de exploração, dominação e discriminação presentes na sociedade, compreendendo-se também essa transformação na perspectiva de uma democracia radical, a qual implica a democratização da própria esfera política no campo da esquerda.

É a existência dos movimentos sociais, nas várias formas de organização, expressão, lutas e capacidade de resistência, que nestes anos de hegemonia neoliberal, crise de paradigmas e de projetos alternativos contribuiu decisivamente para manter acesa a existência de uma esfera política de contestação da ordem atual. É também a existência desses movimentos, no sentido da movimentação de ação política e de idéias, que produz historicamente as condições de realização do Fórum Social Mundial, e neste caso reafirmo que falo do Fórum como um processo. A existência dos movimentos sociais nestas últimas décadas manteve viva também a contestação de um outro postulado neoliberal: o do fim da história.

Pensando então o Fórum Social Mundial a partir de vários significados da história recente e da reconstrução das formas de luta e de organização de projetos libertários e emancipatórios, podemos dizer que ele é um marco nesse caminho. O Fórum também ganha sentido na sua relação com outras formas contemporâneas de contestação da globalização, da superexploração capitalista, da violência das guerras, contra o fundamentalismo religioso, contra o imperialismo americano, e também contra a relação de poder profundamente desigual entre os países do Sul e do Norte. Essas contestações estão no Fórum e em vários outros espaços políticos internacionais e nacionais que se reforçam uns aos outros. O que torna o Fórum cada vez mais um movimento e o que poderá torná-lo cada vez mais estratégico é a sua capacidade de ser contra as agendas neoliberais e imperialistas sem, no entanto, ser determinado por elas. Constrói-se dessa maneira o movimento que se faz cada vez mais permanente e multipolar.

\section{Democracia, conflito e reconhecimento}

O crescimento do Fórum Social Mundial vem junto com os dilemas a serem enfrentados na sua forma de organização e ação. Entre a fragmentação e a confluência, existem várias possibilidades. Os métodos de trabalho político coletivo se aprimoraram entre os movimentos sociais, mas não superaram ainda as polaridades entre um particular de cada um e um geral que está fora ou acima de todos os movimentos. No espaço do segundo Fórum Social Mundial em Porto Alegre era possível observar que estamos ainda 
aprendendo a lidar com essa nova forma de agregação política que se expande e se diversifica sem ter a priori uma determinação programática ou uma direção instituída para definir seus rumos. Mas é um espaço de debate dos acordos e desacordos e, portanto, de enfrentamento dos conflitos, como afirma Collin: "o desacordo, se ele é assegurador e de diálogo, é fecundo. É a unanimidade que será suspeita". ${ }^{2}$

Por outro lado, o processo do Fórum avança, a partir de novas relações políticas que engendram concretamente uma nova perspectiva de ação internacional, de ação massiva, de projetos coletivos, e não é só a partir do Fórum, mas ele contribuiu muito para isso. O que está em causa é como avançar. Quais os sujeitos da transformação neste contexto mundial e quais as estratégias e métodos de ação.

Para o movimento feminista, essa é uma questão crucial por razões históricas. E em relação ao Fórum Social Mundial esse é um espaço onde o feminismo encontra um locus fecundo para tecer suas alianças, idéias com outros sujeitos, mas também para agir no sentido de marcar sua contribuição para uma forma democratizada da política. $O$ internacionalismo do movimento feminista ganha, com o Fórum, tanto uma nova expressão como novas responsabilidades. No geral, temos aí uma relação dialética, em que os movimentos produzem um processo e esse processo reconfigura a dimensão de cada movimento e dos movimentos em geral.

Entre a fragmentação atomizada e os modelos totalitários, temos que inventar processos de democracia radical que produzam a democratização da vida social, o que implica a democratização da política. Porque somos diversos não vamos querer incorrer nos riscos de alcançar uma totalidade, instaurar modelos de futuro, definir um sujeito genérico. Não penso, tampouco, em complementaridade em relação aos movimentos políticos. Acho que essa é uma idéia funcionalista - incompatível com a transformação. A experiência histórica nos mostra que a complementaridade nas relações sociais leva à hierarquia, à desigualdade e à acomodação. Compreendo que o feminismo nos ensina a rejeitar tanto as hierarquias como a complementaridade como formas de relação. Ao invés da complementaridade, proponho o reconhecimento, a solidariedade, a capacidade de enfrentar as diferenças e os conflitos.

Enfrentar o conflito democraticamente é uma condição básica para confluência. Negar o conflito é muitas vezes a negação do outro movimento, de outra posição; o que só fragiliza a luta e diminui a capacidade de resistência. A negação do outro como sujeito contradiz o sentido da transformação e produz um ato de barbárie política. A negação é o desejo de eliminação. A negação já caracteriza uma forma autoritária de relação política.

O Fórum Social é um movimento de ação política pleno de radicalidade porque nesse contexto estão presentes os movimentos que lutam contra todas as formas de opressão, exploração e discriminação presentes em nossa sociedade. Porque revela a multiplicidade de sujeitos e a necessidade de um agir político que leve em conta a autonomia, a contribuição e o valor das causas e de cada forma de organização para a emancipação dos sujeitos e construção de uma sociedade com justiça social e igualdade. É também um espaço aberto às/aos recém-chegadas/os, àquelas/es que ainda não definiram seus pertencimentos, mas querem fazer parte, conhecer, viver uma experiência nova e quem sabe trazer para o coletivo utopias que estavam guardadas pela falta de ter onde partilhá-las. O que quero salientar é que os espaços dos grandes encontros do Fórum Social Mundial também reúnem experiências muitos diferenciadas, sendo para umas/uns apenas o começo.

Pensando o Fórum a partir do pertencimento ao movimento feminista, o que se

\footnotetext{
${ }^{2}$ Françoise COLLIN, 2001, p. 187.
} 
coloca como primeira questão para o debate é a inserção e o reconhecimento desse movimento como sujeito da transformação social. Isso a partir de uma visão dialética da história que nos permita entender a relação entre as várias dimensões do conflito social e as contradições presentes nas diversas formas de enfrentar as desigualdades, as explorações e as opressões.

Entendo que a transformação social é o espaço histórico da confluência dos vários sujeitos políticos. A construção de espaços específicos de confluência é determinada a partir das contradições que temos de enfrentar dentro das condições sociais e históricas de cada contexto. Para uma estratégia política de ação coletiva entre vários sujeitos em defesa de muitas causas, a compreensão das linguagens e dos sentidos de cada movimento é imprescindível para permitir a inteligibilidade entre eles e a capacidade de reunir lutas e manter autonomia.

A questão da relação com os partidos já está posta nos debates do Fórum e sobre o Fórum. Não há a presença orgânica de maneira formalizada. Mas partidos já estão no Fórum através de suas/seus militantes e de duplas militâncias; das relações que mantêm com os movimentos e também através das manifestações que apresentam e de suas bandeiras. No entanto, como sujeito da organização, coordenação, não estão. Isto é, como sujeito instituinte do Fórum. Mas independentemente de estarem ou não, essa relação é claramente colocada como parte desse movimento.

Como afirma Pedro Santana, "os partidos políticos têm incorporado programaticamente as reivindicações dos movimentos, sem no entanto incorporar sua cultura política". ${ }^{3}$ Como se coloca então a relação dos partidos com um espaço que expressa uma nova cultura política e, mais que isso, traz uma espécie de expectativa histórica de apresentar novas formas de ação coletiva baseada em relações políticas igualitárias? Por tradição, os partidos mobilizam os grandes processos coletivos e disputam entre eles a direção. Como se coloca a relação em um processo coletivo cujo poder de aglutinação e contestação está dado pela ação dos movimentos sociais? Não acho que a resposta possa ser dada a priori. O processo histórico se desenrola, e a elaboração ajuda a compreendê-lo e tomar posição diante das questões.

Para o movimento feminista essa sempre foi uma grande questão. No feminismo contemporâneo é marcante, e nos anos 1970 isso ganhou muita expressão. A questão da autonomia, a crítica à forma hierárquica de organização, à dominação masculina no espaço partidário, e finalmente a questão do reconhecimento do próprio movimento como sujeito político são pautas que marcam a história da relação entre feminismo e partidos. No momento, essas questões não estão superadas e devem ser recolocadas nos termos do contexto político atual, no qual as questões feministas estão incorporadas pelos partidos, mas isso não reflete um maior equilíbrio nas relações de poder político entre feminismo e partidos.

É parte da luta das mulheres feministas desfazer as heranças patriarcais que ainda permanecem na organização dos movimentos políticos - mesmo aqueles de proposições libertárias. As formas próprias de atuação do feminismo e a sua negação em aceitar os códigos de ordem de uma política de tradição patriarcal ainda constituem, em muitas circunstâncias, tensões políticas e isolamento. A inserção de temas como a sexualidade e a reprodução como campos de transformação social produzem subversão e conflito na esfera política e repercute na relação do movimento feminista com outros movimentos, considerando-se ainda que há, dentro das várias correntes de pensamento de esquerda, quem não considere, nem do ponto de vista teórico nem do ponto de vista político, as

\footnotetext{
${ }^{3}$ SANTANA, 2003, p. 60.
} 
conexões entre sexualidade, reprodução e produção como parte da dinâmica do sistema capitalista.

Segundo Judith Buttler, ${ }^{4}$ esse é um tema que reaparece com força em espaços de debate no contexto do pensamento de esquerda. Segundo essa autora, há um neoconservadorismo de esquerda que faz uma clivagem entre movimentos políticos e culturais. Nessa clivagem há temas que são considerados 'puramente' culturais. Os movimentos em torno deles não se constituem como políitcos e a dimensão cultural está dissociada da dimensão material da esfera produtiva. Por trás dessa visão há uma abordagem de questões como sexualidade, reprodução e relações entre os sexos separadas das questões materiais da esfera produtiva, portanto consideradas fora do conflito central da exploração capitalista.

Uma análise da realidade social que identifique as várias dimensões ou expressões das desigualdades é necessária no sentido de legitimar as causas políticas dos diversos movimentos sociais, mas também para revelar com mais profundidade e acuidade as teias que se formam para sustentação e reprodução das explorações e dominações presentes no sistema capitalista.

Entender a relação entre sexualidade, reprodução e produção como questões que fazem parte dos planos simbólico e material das relações sociais de exploração e dominação é uma exigência analítica trazida pela politização das várias dimensões do conflito social reveladas pelos movimentos sociais. Com isso, queremos dizer que as relações de produção e acumulação de riquezas, de repressão e discriminação sexual, e o modelo de reprodução não constituem dimensões estanques da vida social, mas, ao contrário, são elementos constitutivos de uma determinada ordem social. A dissociação entre esses campos e entre esses campos e a política é um estratagema do sistema de poder capitalista e patriarcal que, ao fragmentar e dissociar essas várias dimensões, fragiliza as estratégias de resistência. As relações desiguais de classe, raça e gênero são reproduzidas e mantidas a partir de um sistema de poder que se sustenta na produção articulada dessas desigualdades nas esferas cultural e material da vida social, e que ao mesmo tempo produz uma percepção fragmentada dos problemas. Posicionar-se contra esse sistema é, em primeiro lugar, reconhecer as várias formas de desigualdades e discriminações e os seus imbricamentos.

De acordo com Eleni Varikas, ${ }^{5}$ falando da origem do movimento feminista contemporâneo, "a força desse movimento residia principalmente na sua insistência sobre - caráter 'estrutural' da dominação que se manifesta nas relações da vida cotidiana, dominação cuja natureza política tinha sido justamente negada. Não se tratava de opor as 'mentalidades' às 'instituições', mas muito mais de mostrar que a dominação era ao mesmo tempo oculta e reproduzida pelo intermédio de poderosas instituições tais como a família, a separação sexuada entre público e privado, a heterossexualidade institucionalizada, a divisão e a estrutura sexuada do trabalho e do emprego, etc."

Para o feminismo o controle sobre o corpo e a sexualidade foi desde o início um campo de análise e luta política. Desvendar o sofrimento e a violência exercida sobre o corpo das mulheres e as formas de repressão sexual - que abre caminho para a crítica à heterossexualidade como única expressão legítima de relacionamento sexual - constitui um legado do feminismo para uma concepção de transformação social, ao mesmo tempo

\footnotetext{
${ }^{4}$ BUTTLER, 2001.

${ }^{5}$ VARIKAS, 1996, p. 69.
} 
mais radical e mais humana. Um eixo estruturante da desigualdade de gênero é a divisão sexual do trabalho (entre as esferas produtiva e reprodutiva, e no interior delas), a qual não está dissociada do modelo heterossexualidade-procriação que prevaleceu como modelo hegemônico na formação social capitalista.

Mas os temas da sexualidade e da reprodução colocam também o debate sobre a esfera política como campo laico. As feministas o colocam no interior do próprio Fórum. Para o movimento feminista essa é uma questão incontornável. A defesa de direitos nesses campos sempre criou tensões entre o movimento feminista e outros movimentos e partidos políticos. Uma forte razão para isso acontecer é a influência das Igrejas sobre a esfera da política. Em todos os continentes e de maneira variada, essa é uma questão pertinente como uma questão própria da democracia que, doravante, tem de ser enfrentada do plano local ao plano global.

Segundo Francisco de Oliveira, ${ }^{6}$ a construção da cidadania e da democracia são intermináveis, no sentido de que, no momento mesmo em que as aquisições cidadãs e democráticas são confirmadas, recomeça o trabalho de ampliação dos limites já alcançados. Esse recomeço, segundo ele, deve ir no sentido de ampliar o que se adquiriu e não deve ser confundido com o 'eterno retorno, incansável e sem esperanças'. Neste sentido, é importante resgatar que uma das conquistas fundantes da democracia moderna é o Estado Laico. Na perspectiva das lutas emancipátorias e do contexto mundial atual, essa é uma premissa a ser recolocada como valor e como campo de luta para sua realização como condição básica da vida democrática.

\section{Questões finais}

É temerário ou inadequado pensar a ação política sem reconhecer que a participação dos sujeitos se faz em uma esfera pública ainda plena de desigualdades. $O$ acesso à esfera política é uma trajetória desigual a partir da inserção social dos sujeitos. A inserção social também incide sobre as possibilidades materiais e simbólicas de poder de cada organização. Superar a desigualdade como sujeito na esfera política é parte do movimento dialético da construção do próprio sujeito. Existem diferenças de grau de reconhecimento político das diferentes causas e movimentos sociais. Há um sistema de hierarquias que precisa ser transformado por nós.

Na reprodução da vida cotidiana, as desigualdades materiais e a dominação simbólica atuam como meios de produção de alienação e impedem o acesso à participação política. No caso das mulheres há uma tensão entre o tempo de 'agir' do sujeito político e o das tarefas da dupla jornada, dadas pela divisão sexual do trabalho. A falta de tempo funciona como um bloqueio. A constituição das mulheres como sujeito está diretamente vinculada à abertura de novos espaços políticos e à liberação do tempo como ação transformadora. As mulheres negras do movimento feminista têm contribuído decisivamente para revelação e superação das desigualdades nas condições sociais e políticas entre as mulheres que constituem o próprio movimento feminista.

Democratizar a política para uma ação transformadora radical é produzir no interior dos movimentos aos quais pertencemos as condições de igualdade de participação. Dos espaços no Fórum Social Mundial às reuniões em nossas aldeias, vilas, cidades ou no campo temos de romper os bloqueios que impedem o acesso à cidadania política. "E seguramente, para essa nova época, necessitamos detectar novos movimentos - ou os movimentos de

\footnotetext{
${ }^{6}$ OLIVEIRA, 1998.
} 
sempre - que sejam capazes de modificar a cultura, a política. E isso significa democratizarse internamente também. Ou corremos o risco de que os fóruns em geral sejam espaços de certas elites profissionais da antiglobalização ou profissionais das redes internacionais de construção de alternativas. E isso seria uma tragédia. Portanto, se as novas associações e os novos movimentos têm de abrir sua agenda a uma reivindicação global - se têm de ser veículos, transporte de democracia e participação cidadã nas esferas local e internacional - deverão adaptar-se e modificar-se para poderem ser realmente canais e pontes que comuniquem bem. E não elites que capitalizem para si os conhecimentos e as oportunidades que terão nesses lugares."7

Enfim, o Fórum nos obriga a ver o mundo mais complexo e os problemas do mundo mais próximos uns dos outros. Mas o próprio Fórum precisa também ser mais expressivo de todas as partes e problemas do mundo. E parece que esse é o caminho ao se espalhar por todos os continentes e ao mudar de um lugar para outro. No interior dos grandes momentos cabe a todas/os o desafio da via democrática radical.

O sistema capitalista, racista, patriarcal, e o modelo hegemônico de fazer política têm tido uma capacidade incomensurável de produzir sofrimento humano. Enfrentar esse sistema requer antes de tudo uma capacidade imensa de solidariedade e generosidade no interior de nossas confluências e também uma capacidade crítica de combater em nós também as formas e meios herdados da tradição desse sistema.

O desafio da reinvenção da política não se coloca para o processo do Fórum apenas. O Fórum reverbera para o mundo e isso é mais uma razão para instituirmos novas práticas. Na reverberação para o mundo, é necessário que se apresentem as contestações, mas também as propostas e os novos valores, os princípios éticos de um mundo justo. Pois a força do neoliberalismo em manter seu projeto de superexploração e concentração de riqueza, poder e violência está também calcada em um projeto ideológico que contaminou sem dúvida as sociedades do planeta.

A elaboração sobre o processo do Fórum e do seu espalhamento pelo mundo é parte da sua construção e uma fonte concreta de construir seus desdobramentos. Neste sentido, quero resgatar uma passagem da crônica de Barbara di Tommaso sobre o Fórum Social Europeu em Florença, na Itália. "Os problemas que temos diante de nós são enormes, nossas categorias conceituais e políticas são inadequadas (percebemos a cada momento); se adotarmos a ótica de aprender com disponibilidade e humildade, se conseguirmos suspender a ânsia de dizer, tomar posição, resolver, concluir, talvez consigamos extrair o melhor da elaboração, por cada um, dos problemas que dizem respeito a todos. Um movimento competente é possível e já está em ação. Trata-se de reconhecê-lo. [...] Dialogar faz bem. Se dialogamos bem, geramos eventos importantes, de qualidade, que ajudam todos a dar passos adiante. Porque o diálogo (discurso entre pessoas) nos obriga a sermos mais inteligentes, a reconhecermos o outro, a considerarmos sua cultura e suas referências. Não saímos como antes de experiências de diálogo real. Mudamos, para melhor. Em Florença, isso ficou claro. Obrigados a sair de lógicas auto-referentes e narcisistas pela precipitação dos acontecimentos externos, graças ao encontro com outros, recebemos de volta um olhar positivo, gratificante, reconhecido. Que o medo de mudar não nos faça voltar atrás, para a autoguetificação." ${ }^{8}$

Os caminhos estão abertos, nossa capacidade de repensar o mundo e agir sobre ele será tanto melhor quando formos capazes de repensar e reinventar nós mesmas e

${ }^{7}$ Carlés RIERA, 2003, p. 58.

${ }^{8}$ DI TOMMASO, 2003, p. 72. 
nossas práticas.

O momento da ação política transformadora é também o da invenção de novas relações, de construção de subjetividade e, portanto, de invenção coletiva e de invenção de si mesma. Danièle Kergoat reproduz uma elaboração de Collin que, segundo ela, vai mais ou menos nesse sentido: “... as relações sociais de sexo criaram uma 'identidade feminina' que dispensa e mesmo impede as mulheres de inventar suas práticas, de se inventar. Bloquear a capacidade individual e coletiva da invenção de si de mesma, isso volta a escravizar o grupo dominado. E no caso das mulheres, este estado de coisas se encontra tão longe no tempo e é tão espalhado sobre o planeta que é difícil de imaginar, de pensar que um outro mundo seja possível". ${ }^{9}$ Ser autora da invenção de si mesma e do mundo é uma aventura que o feminismo abriu para as mulheres, e essa é uma aventura em curso e que já atravessa o planeta. Para o movimento feminista, portanto, a reinvenção da política está diretamente relacionada à instituição das mulheres como sujeito.

E é Collin ${ }^{10}$ que nos diz que devemos falar sobre o feminismo como uma revolução, uma revolução de outro tipo, sobretudo uma revolução que não usa a violência como meio de transformação. No caminho da Índia e nas outras rotas nacionais, continentais e internacionais que o Fórum vai traçando, o movimento feminista tem uma oportunidade histórica de fortalecer e reinventar o seu internacionalismo, com suas confluências e seus conflitos, enfrentando os conflitos como um meio de se tornar mais forte e tomando a 'revolução' como uma experiência que tem de ser vivida também no seu interior como parte de sua própria constituição permanente de sujeito.

\section{Referências bibliográficas}

BUTLER, Judith. "Simplement culturel?". Actuel Marx, Paris: Presses Universitaires de France, n. 30 (Les rapports sociaux de sexe), p. 201-216, 2001.

COLLIN, Françoise. "Differérence/indifférence des sexes". Actuel Marx, Paris: Presses Universitaires de France, n. 30 (Les rapports sociaux de sexe), p. 183-200, 2001.

DI TOMMASO, Barbara. "Fragmentos de um discurso esperançoso". Democracia Viva, Rio de Janeiro: IBASE, n. 14, p. 70-73, jan. 2003.

KERGOAT, Danièle. "Le rapport social de sexe: de la reproduction des rapports sociaux à leur subversion". Actuel Marx, Paris: Presses Universitaires de France, n. 30 (Les rapports sociaux de sexe), p. 85-100, 2001.

OLIVEIRA, Francisco de. "Entre a terra e o céu: mensurando a utopia?" In: SEMINÁRIO

CIDADANIA, POBREZA E EXCLUSÃO SOCIAL. Petrópolis: Finep/Novib, dez. 1998. p.9-11. Não publicado.

\section{Reflecting on the World Social Forum from a Feminist Perspective}

Abstract: This article presents some questions inspired by the World Social Forum concerned to the relations between social movements and the project of social change, interpreted as a political process to overcoming exploitation, domination and social discrimination. This transformation is comprehended through the perspective of a radical democracy, that is the democratization of the political sphere in the left's field.

Key words: feminist movement, democracy, conflict, transformation, acknowledgement

\footnotetext{
${ }^{9}$ KERGOAT, 2001, p. 93

${ }^{10}$ COLLIN, 2001.
} 